\title{
HERANÇA DA ESTATURA DE PLANTA E DO COMPRIMENTO DA PANÍCULA PRINCIPAL NO CRUZAMENTO ENTRE AVENA SATIVA L. E AVENA STERILIS L. ${ }^{1}$
}

\author{
MÁRCIO PAIM MARIOT ${ }^{2}$, MARIA JANE CRUZ DE MELO SERENO ${ }^{3}$, \\ LUIZ CARLOS FEDERIZZI e FERNANDO IRAJÁ FÉLIX DE CARVALHO ${ }^{4}$
}

\begin{abstract}
RESUMO - A espécie selvagem Avena sterilis L. tem sido amplamente utilizada para cruzamento com aveia cultivada, pela alta afinidade existente entre ambas, o que possibilita um aumento na variabilidade genética e transferência de genes de importância agronômica. Entretanto, caracteres indesejáveis, como a alta estatura e um maior comprimento de panícula, podem ser transferidos à progênie. Nesse sentido, com o objetivo de avaliar a variabilidade genética, bem como a herança em cruzamentos entre Avena sativa L. e Avena sterilis L., foram mensurados os caracteres estatura de planta e comprimento da panícula principal. As variâncias fenotípicas e genéticas foram altas e as variâncias de ambiente foram baixas, proporcionando uma alta herdabilidade no sentido amplo. $\mathrm{O}$ efeito gênico de aditividade foi o mais importante para explicar a variação genética em ambos os caracteres.
\end{abstract}

Termos para indexação: cruzamento interespecífico, caracteres agronômicos.

\section{INHERITANCE OF PLANT HEIGHT AND MAIN PANICLE LENGTH FOR THE CROSSES BETWEEN AVENA SATIVA L. AND AVENA STERILIS L.}

\begin{abstract}
The wild species Avena sterilis $\mathrm{L}$. has been widely used for crossing with cultivated oat The high affinity between them enables an increase in genetic variability and transference of important agronomic genes. However, undesirable characters such as great plant height and length of the panicle can be transferred to progenies. These characters were analysed to evaluate the genetic variability and inheritance in crossing between Avena sativa L. and Avena sterilis L. Estimates of phenotypical and genetical variances were high while the environmental variance was low, providing a high broad sense heritability. The additive gene effect was the most important for explaining the genetic variation for both characters
\end{abstract}

Index terms: interspecific crossing, agronomic characters.

\section{INTRODUÇÃO}

A cultura da aveia (Avena spp.) é de grande importância econômica no sul do Brasil, onde um aumento na área semeada tem sido observado nos últimos anos (Anuário Estatístico do Brasil, 1992). Além

\footnotetext{
${ }^{1}$ Aceito para publicação em 2 de junho de 1998.

Extraído da dissertação de Mestrado do primeiro autor apresentada à Faculdade de Agronomia, UFRGS

${ }^{2}$ Eng. Agr., M.Sc., Rua Álvaro Chaves, 363, CEP 96010-760 Pelotas, RS.

${ }^{3}$ Bióloga, Dr., Dep. de Plantas de Lavoura, Fac. de Agronomia, UFRGS, Caixa Postal 776, CEP 91509-900 Porto Alegre, RS.

${ }^{4}$ Eng. Agr., Dr., Dep. de Plantas de Lavoura, Fac. de Agronomia, UFRGS.
}

disso, progressos genéticos satisfatórios foram alcançados em rendimento de grãos.

Os programas de melhoramento genético de aveia objetivam atualmente a obtenção de plantas de porte baixo, precoces, com alto rendimento e qualidade de grãos, assim como resistência a moléstias, principalmente ferrugem-da-folha e do colmo (Carvalho \& Federizzi, 1989)

A Universidade Federal do Rio Grande do Sul atualmente está utilizando a espécie selvagem Avena sterilis $\mathrm{L}$. em cruzamentos artificiais com variedades de aveia cultivada, com o propósito de ampliar a variabilidade genética e introduzir genes específicos de importância agronômica.

O gênero Avena ocorre em três níveis de ploidia: diplóide $(2 n=2 x=14)$, tetraplóide $(2 n=2 x=28)$ e hexaplóide $(2 \mathrm{n}=6 \mathrm{x}=42)$ (Holden, 1979; Tavares et al., 
1993). Segundo os autores, as espécies Avena sativa L. e Avena sterilis do grupo hexaplóide apresentam os mesmos genomas, AACCDD, e a Avena sterilis provavelmente foi a que deu origem a todo $o$ grupo hexaplóide na evolução da aveia.

Entre os caracteres de arquitetura de planta que 0 melhoramento genético procura para formar um ideotipo, a baixa estatura é a principal. A introdução de genes com vistas a porte baixo resultou em um aumento no rendimento de grãos pela redução no acamamento e aumento no índice de colheita (Federizzi \& Qualset, 1989). Esses autores verificaram que poucos genes maiores são responsáveis pela redução na estatura de planta em aveia e observaram altas variâncias genética e fenotípica nos cruzamentos realizados. Resultado semelhante foi obtido por Bertagnolli (1992), em que os efeitos aditivos foram de grande importância para todos os cruzamentos.

A ação de um gene maior com vistas a baixa estatura em aveia foi observada por Pateerson et al. (1963) e Marshall \& Murphy (1981).

Ao avaliar a estatura de planta em genótipos de Avena sativa e Avena sterilis, Tavares (1991) verificou que as variedades cultivadas apresentaram menores valores quanto a esse caráter, quando comparadas com os genótipos selvagens, e que existe variabilidade genética dentro de cada espécie. O comprimento de panícula também foi avaliado e foi observada ampla variabilidade genética, com as introduções selvagens apresentando panículas maiores do que os genótipos cultivados, com um reduzido número de grãos por panícula.

A maior estatura de planta e comprimento da panícula de Avena sterilis são indesejáveis, podendo ser transferidas para as progênies em programas de melhoramento que utilizam cruzamentos interespecíficos. Desta forma, é importante um estudo genético da herança desses caracteres.

O objetivo deste trabalho foi avaliar a variabilidade genética em estatura de planta e comprimento da panícula principal e estimar alguns parâmetros genéticos para avaliação da herança desses caracteres em cruzamentos de Avena sativa x Avena sterilis.

\section{MATERIAL E MÉTODOS}

Foram utilizados três genótipos de Avena sativa (UFRGS 7, UFRGS 8 e UPF 7) e três de Avena sterilis
(I-377, I-378, originários de Israel e I-ARG, da Argentina). As cultivares UFRGS 7 e UFRGS 8, lançadas pela Universidade Federal do Rio Grande do Sul, e UPF 7, desenvolvida na Universidade de Passo Fundo, são recomendadas para a Região Sul do Brasil.

Os cruzamentos interespecíficos foram realizados por Tavares (1991) em 1988 e 1989, com a utilização de Avena sativa como planta-mãe, além de um retrocruzamento $\left(\mathrm{RC}_{1} \mathrm{~F}_{1}\right)$ em 1989 para essa espécie e obtenção da geração $\mathrm{F}_{2}$.

No ano agrícola de 1991 foram semeadas na Faculdade de Agronomia-UFRGS, as gerações $F_{1}, R_{1} F_{1}$ e $F_{2}$ para, respectivamente, aumentar a população de $\mathrm{F}_{2}$ e obter as gerações $\mathrm{RC}_{1} \mathrm{~F}_{2}$ e $\mathrm{F}_{3}$. No verão de 1992 foram semeadas as gerações $\mathrm{RC}_{1} \mathrm{~F}_{1}$ para aumentar a população de $\mathrm{RC}_{1} \mathrm{~F}_{2} \mathrm{e}$ $\mathrm{RC}_{1} \mathrm{~F}_{2}$, a fim de obter a geração $\mathrm{RC}_{1} \mathrm{~F}_{3}$. Todas as sementes utilizadas foram vernalizadas pelo método proposto por Lagos et al. (1982).

No ano agrícola de 1992, foi estabelecido um experimento em área do Departamento de Plantas de Lavoura, na Estação experimental Agronômica da UFRGS, localizado em Eldorado do Sul,RS, para avaliar os caracteres agronômicos dos genótipos parentais e das gerações segregantes resultantes das hibridizações interespecíficas.

Os tratamentos (cruzamentos) foram instalados em delineamento de blocos completamente casualizados, com duas repetições para cada cruzamento.

Foram semeadas quatro linhas de cada genótipo parental por cruzamento, e para as gerações segregantes $\mathrm{F}_{2}, \mathrm{RC}_{1} \mathrm{~F}_{2}$ e $\mathrm{RC}_{1} \mathrm{~F}_{3}$, as linhas variaram de acordo com a disponibilidade de sementes. Cada família $\mathrm{F}_{3}$, originária de uma planta $\mathrm{F}_{2}$, foi semeada em duas linhas por repetição.

Os caracteres analisados de cada planta individualizada foram: estatura de planta e comprimento da panícula principal.

Os cruzamentos avaliados quanto à estatura envolveram todas as combinações entre os genótipos cultivados e selvagens, com exceção de UFRGS 7 x I-ARG e UFRGS 8 $x$ I-ARG, em virtude do reduzido número de plantas nesses cruzamentos. Com relação ao comprimento da panícula principal, foram analisados apenas os cruzamentos UFRGS 7 x I-377, UFRGS 7 x I-378 e UPF 7 x I-ARG, pois os demais não foram totalmente colhidos em decorrência do alto número de quebra de plantas após a maturação. As populações de retrocruzamento foram obtidas apenas nos cruzamentos envolvendo o genótipo cultivado UFRGS 7.

Estimaram-se os efeitos gênicos dos caracteres pelo método joint scaling test, segundo Mather \& Jinks (1982): $\overline{\mathrm{P}_{1}}=\mathrm{m}+\mathrm{a} ; \overline{\mathrm{P}_{2}}=\mathrm{m}-\mathrm{a} ; \overline{\mathrm{F}_{2}}=\mathrm{m}+1 / 2 \mathrm{~d} ; \overline{\mathrm{F}_{3}}=\mathrm{m}+1 / 4 \mathrm{~d} ;$ $\overline{R_{1} F_{2}}=m+1 / 2 a+1 / 4 d ; \overline{R_{1} F_{3}}=m+1 / 2 a+1 / 8 d ;$ onde, 
$\overline{\mathrm{P}_{1}}, \overline{\mathrm{P}_{2}}, \overline{\mathrm{F}_{2}}, \overline{\mathrm{F}_{3}}, \overline{\mathrm{RC}_{1} \mathrm{~F}_{2}}$ e $\overline{\mathrm{RC}_{1} \mathrm{~F}_{3}}$ correspondem à média de cada uma das gerações; $\mathrm{m}=$ média geral; $\mathrm{a}=$ efeito de aditividade e $\mathrm{d}=$ efeito de dominância. Os efeitos de aditividade e dominância foram estimados a partir das gerações disponíveis, utilizando o método dos quadrados mínimos ponderados (Mather \& Jinks, 1982).

Para cada cruzamento foi testado o modelo com três parâmetros, desconsiderando os efeitos epistáticos, sendo o ajuste do modelo testado pelo teste de qui-quadrado, com GL = número de gerações - número de parâmetros estimados. A significância do parâmetro genético foi verificada pelo teste $\mathrm{t}$, sendo $\mathrm{t}=\hat{\mathrm{e}} / \sigma$, onde $\hat{\mathrm{e}}=$ estimativa do parâmetro e $\sigma=$ desvio padrão do parâmetro.

As variâncias de ambiente $\left(\sigma^{2} \mathrm{e}\right)$, genética $\left(\sigma^{2} \mathrm{~g}\right)$ e fenotípica $\left(\sigma^{2} \mathrm{p}\right)$, além da herdabilidade no sentido amplo $\left(\mathrm{h}^{2}{ }_{\mathrm{a}}\right)$ também foram estimadas pelas equações propostas por Allard (1960):

$\sigma^{2} \mathrm{e}=\left(\sigma^{2} \mathrm{P}_{1}+\sigma^{2} \mathrm{P}_{2}\right) / 2 ; \sigma^{2} \mathrm{p}=\sigma^{2} \mathrm{~F}_{2} ; \sigma^{2} \mathrm{~g}=\sigma^{2} \mathrm{p}-\sigma^{2} \mathrm{e} ;$ $\mathrm{h}^{2}{ }_{\mathrm{a}}=\left(\sigma^{2} \mathrm{p}-\sigma^{2} \mathrm{e}\right) / \sigma^{2} \mathrm{p}$; onde $\sigma^{2} \mathrm{P}_{1}=$ variância do pai Avena sativa; $\sigma^{2} \mathrm{P}_{2}=$ variância do pai Avena sterilis; $\sigma^{2} \mathrm{~F}_{2}=$ variância da geração $\mathrm{F}_{2}$.

\section{RESULTADOS E DISCUSSÃO}

A espécie selvagem Avena sterilis apresentou maior estatura de planta e comprimento da panícula principal do que Avena sativa, com exceção do genótipo I-ARG, que é semelhante à espécie cultivada (Tabela 1).

Uma ampla variabilidade genética foi evidenciada entre os genótipos parentais avaliados, detectado pelo teste de t entre as médias dos pais em ambos os caracteres (Tabela 1). Houve diferença significativa entre a maioria dos genitores, com exceção de UPF 7 com I-378 e I-ARG, em estatura de planta, e UPF 7 e I-ARG, em comprimento da panícula principal. Resultados semelhantes foram observados por Tavares (1991), em experimento desenvolvido na Faculdade de Agronomia da UFRGS, os quais revelaram que a estatura foi maior do que no presente trabalho em todos os genótipos, cultivados e selvagens, evidenciando a grande influência do ambiente na expressão desse caráter.

Quanto à estatura de planta, as variâncias fenotípicas e genéticas foram altas, com valores semelhantes em todos os cruzamentos e as variâncias de ambiente baixas e semelhantes, exceto nos cruzamentos UFRGS 7 x I-377 e UPF 7 x I-377 (Tabela 2). O cruzamento UPF 7 x I-378 mostrou os maiores valores de variância genética e fenotípica, enquanto a combinação UFRGS 7 com I-378 apresentou os menores. A elevada variância genética e a baixa variância de ambiente encontradas em todos os cruzamentos proporcionaram uma alta herdabilidade no sentido amplo (Tabela 2). As combinações de UFRGS 7 com I-377 e UPF 7 com I-377 mostraram uma menor herdabilidade no sentido amplo, pela variância de ambiente ter sido maior. Elevadas variâncias genéticas e fenotípicas também foram observadas por Federizzi \& Qualset (1989) em cruzamentos entre variedades de Avena sativa.

Com relação ao comprimento da panícula principal, as variância fenotípicas e genéticas foram altas, com valores semelhantes em todos os cruzamentos, e as variâncias de ambiente foram baixas, proporcionando uma herdabilidade relativamente alta no sentido amplo (Tabela 2). O cruzamento UFRGS 7 x I-377 revelou uma herdabilidade maior, por ter apresentado uma alta variância genética e a menor variância de ambiente.

O modelo genético de três parâmetros se ajustou a todos os cruzamentos, em ambos os caracteres, sendo os efeitos de epistasia não significativos (Tabela 3). Com relação à estatura de planta, o efeito aditivo foi o mais importante para explicar a variação genética na maioria dos cruzamentos, e na combinação UPF 7 com I-377, o efeito de dominância também foi importante na redução da estatura de planta, por ter apresentado sinal negativo. Os cruzamentos UPF 7 x I-378 e UPF 7 x I-ARG não apresentaram efeito aditivo significativo, podendo ter ocorrido um cancelamento dos efeitos. Em estudo da herança da estatura de planta em genótipos de aveia cultivada, Bertagnolli (1992) verificou a importância de outros efeitos, pela não-adequação ao modelo de três parâmetros na maioria dos cruzamentos.

Quanto ao caráter comprimento da panícula principal, a aditividade foi o único efeito importante em todos os cruzamentos (Tabela 3 ).

O porte baixo e menor comprimento de panícula é uma das características procuradas no melhoramento genético de aveia (Carvalho \& Federizzi, 1989). A redução do tamanho da panícula é importante, pois determina um maior número de grãos por panícula, aumentando o rendimento. 
A obtenção de linhagens com porte baixo e comprimento de panícula do tipo cultivado é possível em programas que utilizem cruzamentos entre Avena sativa e Avena sterilis, uma vez que o efeito aditivo foi o mais importante. Assim, a herdabilidade no sentido restrito deve ser alta, sendo importante para o melhoramento, pois a aditividade é fixada na seleção, ao contrário do efeito de dominância. Plantas de porte mais baixo que os genótipos parentais de Avena sativa foram encontrados em famílias F3, indicando segregação transgressiva.

A introdução do genótipo selvagem I-ARG se apresentou semelhante aos cultivados, tanto na estatura de planta quanto no comprimento da panícula principal. Como tal genótipo foi coletado próximo a uma estação experimental de aveia na Argentina, pode ter ocorrido fluxo gênico entre as duas espécies, reduzindo a estatura e o comprimento da panícula de I-ARG. O genótipo foi considerado promissor para utilização em programas de melhoramento de aveia por Tavares (1991), pela aproximação com a espécie cultivada. Entretanto, apresentam suscetibilidade à ferrugem- da-folha e do colmo, tornando inadequada sua utilização em cruzamentos com genótipos de Avena sativa.

A ampla diversidade genética evidenciada nos caracteres avaliados mostra a importância da utilização de Avena sterilis em cruzamentos com Avena sativa, para ampliar a variabilidade e para a transferência de genes de importância agronômica. Além disso, é possível selecionar plantas com algumas características importantes da espécie selvagem,

TABELA 1. Média dos genótipos parentais e valor do teste de $\mathbf{t}$ dos caracteres estatura de planta (cm) e comprimento da panícula principal (cm) dos cruzamentos interespecíficos em aveia. UFRGS, 1993.

\begin{tabular}{|c|c|c|c|c|c|c|c|c|}
\hline \multicolumn{3}{|c|}{ Genitores } & \multicolumn{3}{|c|}{ Estatura de planta } & \multicolumn{3}{|c|}{ Comprimento da panícula principal } \\
\hline $\begin{array}{c}\mathrm{P}_{1} \\
(\text { A. sativa } \mathrm{L} .)\end{array}$ & vs & $\begin{array}{c}\mathrm{P}_{2} \\
\text { (A. sterilis L.) }\end{array}$ & $\overline{\mathrm{P}_{1}}$ & $\overline{\mathrm{P}_{2}}$ & $\begin{array}{c}\text { Valor do } \\
\text { teste } \mathrm{t}\end{array}$ & $\overline{\mathrm{P}_{1}}$ & $\overline{\mathrm{P}_{2}}$ & $\begin{array}{c}\text { Valor do } \\
\text { teste } \mathrm{t}\end{array}$ \\
\hline UFRGS-7 & vs & $\mathrm{I}-377$ & 95,63 & 164,50 & $6,87 * *$ & 59,03 & 113,00 & $9,05 * *$ \\
\hline UFRGS-7 & vs & $\mathrm{I}-378$ & 97,13 & 154,71 & $7,26 * *$ & 59,16 & 106,13 & $6,35 * *$ \\
\hline UPF-7 & vs & I-ARG & 129,71 & 129,44 & 0,04 & 87,79 & 75,09 & 1,76 \\
\hline UPF-7 & vs & $\mathrm{I}-377$ & 127,17 & 164,35 & $3,41 * *$ & - & - & - \\
\hline UPF-7 & vs & $\mathrm{I}-378$ & 137,70 & 146,50 & 1,04 & - & - & - \\
\hline UFRGS-8 & vs & I-377 & 122,83 & 168,96 & $5,88 * *$ & - & - & - \\
\hline UFRGS-8 & vs & $\mathrm{I}-378$ & 117,16 & 154,67 & $4,81 * *$ & - & - & - \\
\hline
\end{tabular}

** Significativo a $1 \%$ de probabbilidade.

TABELA2. Estimativas das variâncias fenotípicas da $\mathbf{F}_{2}\left(\sigma^{2} \mathbf{F}_{2}\right)$, genética $\left(\sigma^{2} \mathbf{g}\right)$ e de ambiente $\left(\sigma^{2} \mathbf{e}\right)$ e herdabilidade no sentido amplo $\left(\mathrm{h}^{2}{ }_{\mathrm{a}}\right)$ dos carateres estatura de planta e comprimento da panícula principal dos cruzamentos interespecíficos de aveia. UFRGS, 1993.

\begin{tabular}{|c|c|c|c|c|c|c|c|c|c|c|}
\hline \multicolumn{3}{|c|}{ Cruzamentos } & \multicolumn{4}{|c|}{ Estatura de planta } & \multicolumn{4}{|c|}{ Comprimento da panícula principal } \\
\hline & & & $\sigma^{2} F_{2}$ & $\sigma^{2} g$ & $\sigma^{2} \mathrm{e}$ & $\mathrm{h}_{\mathrm{a}}^{2}$ & $\sigma^{2} F_{2}$ & $\sigma^{2} \mathrm{~g}$ & $\sigma^{2} \mathrm{e}$ & $\mathrm{h}_{\mathrm{a}}^{2}$ \\
\hline UFRGS-7 & $\mathrm{x}$ & I-377 & 304,86 & 204,19 & 100,67 & 0,67 & 129,61 & 94,08 & 35,53 & 0,73 \\
\hline UFRGS-7 & $\mathrm{x}$ & $\mathrm{I}-378$ & 217,08 & 154,11 & 62,97 & 0,71 & 173,08 & 118,31 & 54,77 & 0,68 \\
\hline UPF-7 & $\mathrm{x}$ & I-ARG & 385,39 & 336,39 & 48,99 & 0,87 & 139,22 & 87,39 & 51,83 & 0,63 \\
\hline UPF-7 & $\mathrm{x}$ & $\mathrm{I}-377$ & 358,41 & 239,34 & 119,07 & 0,67 & - & - & - & - \\
\hline UPF-7 & $\mathrm{x}$ & I-378 & 466,50 & 394,49 & 72,01 & 0,85 & - & - & - & - \\
\hline UFRGS-8 & $\mathrm{x}$ & I-377 & 314,87 & 253,35 & 61,52 & 0,80 & - & - & - & - \\
\hline UFRGS-8 & $\mathrm{x}$ & I-378 & 328,33 & 267,61 & 60,72 & 0,81 & - & - & - & - \\
\hline
\end{tabular}


TABELA3. Ação gênica e valores de qui-quadrado para o ajuste do modelo de três parâmetros dos carateres estatura de planta e comprimento da panícula principal dos cruzamentos interespecíficos em aveia. UFRGS, 1993.

\begin{tabular}{|c|c|c|c|c|c|}
\hline \multirow[t]{2}{*}{ Caráter/cruzamentos } & \multicolumn{3}{|c|}{ Parâmetros genéticos ${ }^{1}$} & \multirow[t]{2}{*}{$\chi^{2}$} & \multirow[t]{2}{*}{$\mathrm{P}$} \\
\hline & $\mathrm{m}$ & $\mathrm{a}$ & $\mathrm{d}$ & & \\
\hline \multicolumn{6}{|l|}{ Estatura de planta } \\
\hline UFRGS-7 x I-377 & 132,0 & $-33,1 * *$ & 7,2 & 2,65 & $0,25-0,50$ \\
\hline UFRGS-7 x I-378 & 126,6 & $-28,8 * *$ & 5,5 & 1,14 & $0,75-0,90$ \\
\hline UFRGS-8 x I-377 & 145,2 & $-23,2 * *$ & $-37,7$ & 0,78 & $0,25-0,50$ \\
\hline UFRGS-8 x I-378 & 136,0 & $-18,8 * *$ & $-15,3$ & 0,03 & $0,75-0,90$ \\
\hline UPF-7 x I-377 & 145,8 & $-18,6^{* *}$ & $-17,9 * *$ & 0,001 & $>0,95$ \\
\hline UPF-7 x I-378 & 141,5 & $-4,4$ & $-40,1$ & 0,43 & $0,50-0,75$ \\
\hline UPF-7 x I-ARG & 129,5 & 0,1 & $-9,4$ & 0,01 & $>0,90$ \\
\hline \multicolumn{6}{|l|}{ Comp. pan. principal } \\
\hline UFRGS-7 x I-377 & 86,4 & $-26,5^{* *}$ & 7,1 & 2,08 & $0,50-0,75$ \\
\hline UFRGS-7 x I-378 & 82,9 & $-22,9 * *$ & 17,5 & 0,58 & $0,75-0,90$ \\
\hline UPF-7 x I-ARG & 81,3 & $6,3 * *$ & 3,9 & 0,01 & $0,90-0,95$ \\
\hline
\end{tabular}

${ }^{1} \mathrm{~m}$ : média geral; a: efeito de aditividade; d: efeito de dominância

**Significativo pelo teste $\mathrm{t}$ a $1 \%$ de probabilidade.

mantendo os caracteres desejáveis da aveia cultivada, pela recombinação genética entre as duas espécies.

\section{CONCLUSÕES}

1. As variâncias genéticas e fenotípicas são altas e a de ambiente é baixa, proporcionando uma elevada herdabilidade no sentido amplo em ambas as características avaliadas.

2. O efeito aditivo é o mais importante para explicar a variação genética dos caracteres analisados.

\section{REFERÊNCIAS}

ALLARD, R.W. Principles of plant breeding. New York: J. Wiley, 1960. 381p.

ANUÁRIO ESTATÍSTICO DO BRASIL. Rio de Janeiro: IBGE, 1992. 1022p.

BERTAGNOLLI, P.F. Análise genética de caracteres adaptativos em aveia (Avena sativa L.). Porto Alegre: UFRGS, Faculdade de Agronomia, 1992. 114p. Tese de Doutorado.
CARVALHO, F.I.F.; FEDERIZZI, L.C. Evolução da cultura de aveia no sul do Brasil. Trigo e Soja, Porto Alegre, v.102, p.16-19, 1989.

FEDERIZZI, L.C.; QUALSET, C.O. Genetics of plant height reduction and panicle type in oat. Crop Science, Madison, v.29, p.551-557, 1989.

HOLDEN, J.H.W. Oats. Avena spp. (Gramineae Aveneae). In: SIMMONDS, N.W. (Ed.). Evolution of crop plants. New York: Longman, 1979. 339p.

LAGOS, M.B.; FEDERIZZI, L.C.; CARVALHO, F.I.F. de; NODARI, R.O. Mecanismos de indução à reprodução sexual em trigo. Pesquisa Agropecuária Brasileira, Brasília, v.17, n.10, p.1491-1496, out. 1982.

MARSHAL, H.G.; MURPHY, C.F. Inheritance of dwarfness in three oat crosses and relationship of heigth to panicle and culm lenght. Crop Science, Madison, v.21, p.335-338, 1981.

MATHER, S.K.; JINKS, J.L. Biometrical Genetics. Cambridge: Univ. Press, 1982. 396p

PATEERSON, F.L.; SCHAFER, J.F; CALDWELL, R.M.; COMPTON, L.E. Inheritance of panicle type, height and straw strenght of derivatives of scotland club oats. Crop Science, Madison, v.3, p.555-558, 1963. 
TAVARES, M.J.C.M.S. Variabilidade genética em Avena sativa L., Avena sterilis $\mathbf{L}$. e em seus híbridos: avaliações agronômicas, morfológicas, citogenéticas e eletroforéticas. Porto Alegre: UFRGS, Departamento de Genética, 1991. 141p. Tese de Doutorado.
TAVARES, M.J.C.M.S.; ZANETTINI, M.H.B.; CARVALHO, F.I.F. de. Origem e evolução do gêneroAvena: suas implicações no melhoramento genético. Pesquisa Agropecuária Brasileira, Brasília, v.28, n.4, p.499-507, abr. 1993. 